\title{
Consumers' Attitudes Towards Locally Manufactured High Involvement Products: A Systematic Review
}

\author{
Anyanwu Hilary Chinedu ${ }^{1}$, Sharifah Azizah Haron ${ }^{1,2}$, Ahmad Hariza Hashim ${ }^{1}$, Jo Ann $\mathrm{Ho}^{3}$ \\ ${ }^{1}$ Department of Resource management and Consumer Studies, Faculty of Human Ecology, Universiti Putra \\ Malaysia, Serdang Selangor, Malaysia \\ ${ }^{2}$ Malaysian Research Institute on Aging (MyAgeing ${ }^{\mathrm{TM}}$ ), Universiti Putra Malaysia, Serdang Selangor, Malaysia \\ ${ }^{3}$ School of Business and Economics, Universiti Putra Malaysia, Serdang Selangor, Malaysia \\ Correspondence: Sharifah Azizah Haron, Department of Resource Management and Consumer Studies, Faculty \\ of Human Ecology, Universiti Putra Malaysia, 43400 UPM Serdang, Selangor, Malaysia. E-mail: \\ sh.azizah@upm.edu.my
}

Received: September 22, 2020

doi:10.5539/ass.v16n12p80
Accepted: November 16, $2020 \quad$ Online Published: November 30, 2020

URL: https://doi.org/10.5539/ass.v16n12p80

\begin{abstract}
The increased level of market globalization has necessitated inculcation of positive attitudes towards locally manufactured high involvement products in consumers. While several governments are concerned about this, scholars have also given attention to this development and as a result, a need to ascertain what actually instigates consumers' attitudes towards locally manufactured high involvement products such as: automobiles, houses, and mobile services through systematic review of extant literatures. A systematic literature review that involved comprehensive search of four databases utilized eight eligible studies to conclude that the influence of collectivism and consumer ethnocentrism (CE) on attitude towards locally manufactured high involvement products is a psychological process. The review also revealed that collectivism and CE catalyze consumers' attitudes towards locally manufactured high involvement products through emotional and rational temperaments. Implications of the findings are discussed with suggestion for further studies.
\end{abstract}

Keywords: attitude towards local products, collectivism, consumer ethnocentrism, locally manufactured high involvement products

\section{Introduction}

Market globalization has depleted some economies due to consumers' unfavorable attitudes towards locally manufactured products. This generates a great concern to many governments and has been demonstrated through several campaigns such as: the buy locally made campaign in Slovakia (Saffu, Walker, \& Mazurek, 2010); buy Malaysian products' campaign (The Ministry of Finance Malaysia, 2019); buy Australian made campaign (Cameron \& Elliott, 1998). The encouragement of buy local by several governments speaks volume of this campaign's prominence (Elliott \& Cameron, 1994), which is aimed at inculcating positive/favorable attitudes towards locally manufactured products among consumers. While consumers' attitudes towards locally manufactured products keep grabbing significant consideration from researchers (e.g.: Vincent-Osaghae \& Ugiagbe, 2018; Correa \& Parente-Laverde, 2017; He \& Wang 2015), economic effects of consumers' attitudes to a nation would be felt more if the products are high involvement products. In the sense that acquisition of high involvement products gulps a significant amount of resources from consumers, and should these resources be expended, it could as well boost a nation's economy if the purchased high involvement products are manufactured locally. This has been proven in many countries where high involvement products have contributed to national development. The present review defines high involvement products as those products (examples: cars, houses, personal computers, fashion clothing, insurance, and mobile services) that require extensive thought that are tied to a consumer's ego and self-image before making a purchase decision. For instance, automobile advancements have made great contributions to national economic development and significantly benefitting consumers (Chang, Liao, \& Wu, 2017). Indeed, all these are more feasible when high involvement products are manufactured locally, and are believed to hinge on consumers' attitudes towards locally manufactured high involvement products. 
The Theory of Planned Behavior and Theory of Reasoned Action have consistently pointed at behavioral beliefs and outcome evaluations as antecedents of attitude towards an object or action (Ajzen, 1991; Fishbein \& Ajzen, 1975). This reinforces the notion that cognitive evaluations precede emotional responses (Bagozzi, Gopinath, \& Nyer, 1999; Lazarus, 1991). It implies that, consumers' attitudes towards locally manufactured high involvement products are determined by consumers' pre-assessment of cogent beliefs of the pros and cons of a certain disposition towards locally manufactured high involvement products. In a marketing context, attitude is simply a composite of a consumer's beliefs, feelings, and conations towards some products within a market (Perner, 2010). As a result, consumers ponder on issues related to their intrinsic interests prior to adopting a particular attitude; hence, attitudes towards locally manufactured automobiles could be seen as consumers' psychic extrapolation on the importance of maintaining their heritage and the success of their World through patriotic engagements.

While attitude plays essential roles in human life and constitutes a large part of individuals' daily thoughts and emotions (Eagly \& Chaiken, 2007), extant studies (Yildiz, Heitz-Spahn, \& Belaud, 2018; Ramadania, Gunawan, \& Rustam, 2015) have shown that consumers with high ethnocentric tendencies have more favorable attitudes towards local products. Consumer ethnocentrism has a different affective element called emotional (Acharya \& Elliott, 2003), and ethnocentrism is an attitudinal concept that embroils a stout sense of in-group self-centeredness and self-importance (Bizumic, Duckitt, Popadic, Dru, \& Krauss, 2008).

Similarly, cultural value orientation plays a significant role in consumer decision making because it is an antecedent of psychological process (Triandis, 2000). Cultural values affect consumer attitudes (Koubaa, Ulvoas \& Chew, 2011), and comprises of six dimensions namely: power distance, uncertainty avoidance, individualism versus collectivism, masculinity versus femininity, long-term versus short-term orientation, and indulgence versus restraint (Hofstede, Hofstede, \& Minkov, 2010). Research has highlighted the significance of individualism versus collectivism dimension (Triandis, 2001), such as: in cultural and psychological studies (Earley \& Gibson, 1998); and cultural and consumer studies (Huang \& Lu, 2015). Specifically, collectivism has a direct significant relationship with attitude (Sreen, Purbey, \& Sadarangani, 2018), and is believed to positively embolden consumers' attitudes towards locally manufactured high involvement products due to its underlying beliefs.

Relying on Perner (2010) and the tri-component model of attitude (Rosenberg \& Hovland, 1969), consumer attitudes entails summation of beliefs about a product, feelings about a product, and conations towards a product which in other words are interdependent on each other. In the wake of attitudes components' inextricable link with each other, it becomes imperative to review how consumer ethnocentrism and collectivism is viewed in relation to locally manufactured high involvement products, and the essence of understanding ethnocentrism and collectivism from Triandis lens "an antecedent of a psychological process"; hence, both consumer ethnocentrism and collectivism are anticipated dimensions of a psychological process. In order to ensure maximum benefit of manufacturing high involvement products such as automobiles locally, it is essential to offer a robust view of the advantages of displaying positive attitudes towards locally manufactured high involvement products, its effects on both consumers and local society, and consequently use it as a baseline in policies aimed at sustaining national economy. Therefore, the present systematic review attempts to establish a logical answer towards these hypotheses via synthesization of extant pragmatic studies.

Review question: Is the acclaimed influence of consumer ethnocentrism and collectivism on consumers' attitudes towards locally manufactured high involvement products truly a psychological process? If yes, in what way do they catalyze consumers' attitudes?

\section{Methods}

This section covers the approaches used in identifying and screening the databases of interest with the specified keywords based on the review scope.

Search Strategy: An in-depth search of four databases (Science Direct, Emerald Insight, Springer Link, Scopus) was conducted for potentially relevant articles published between 2009 and 2018.

Keywords: "Cultural values*" OR "Collectivism*" OR "Ethnocentrism*" AND "Attitude towards Locally Manufactured Automobiles*" OR "Attitude towards Locally Manufactured Products*”.

Scope of Review: The present review encompasses studies conducted between 2009 and 2018. Decision to review studies conducted in the last decade is based on the present review's interest to ascertain the static or dynamic nature of the influence of collectivism and consumer ethnocentrism on consumers' attitudes towards locally manufactured high involvement products in modern marketplaces. Review of ten years range of extant studies is believed to be instrumental in ascertaining if a significant paradigm shift from Triandis' position exists 
and its direction among contemporary consumers.

Inclusion and Exclusion Criteria: Studies were incorporated in the current review if they met the following inclusion criteria: (i) comprised a sample of consumers or potential consumers; (b) investigated attitude towards locally high involvement products or domestic brands as outcome variable; (c) investigated the effects or relationship between collectivism or consumer ethnocentrism and attitude towards locally manufactured high involvement products or domestic brands; (d) evaluated consumer ethnocentrism or collectivism as a predictor of attitude towards locally manufactured high involvement products or domestic brands; (e) analyzed components or antecedents of either ethnocentrism or collectivism as a psychological substrate of consumers' attitudes towards locally manufactured high involvement products or domestic brands; (f) qualitative or quantitative research approach, correlational, cross-sectional, case study, comparative, exploratory; and (g) published in a peer reviewed full-text journal from 2009 to 2018. On the other hand, studies were excluded from the review if they were: (a) theoretical or conceptual papers (without any empirical finding); (b) were published in a different language from English; (c) did not study the direct association/effect of consumer ethnocentrism or collectivism on attitude towards locally manufactured high involvement products or domestic brands; (d) had a sample size less than 200 respondents for quantitative studies and 10 informers for qualitative studies, (e) studies that were conducted before 2009 or after 2018, and (f) studies that did not investigate consumers' attitudes on locally manufactured high involvement products or domestic brands; and $(\mathrm{g})$ studies that utilized migrants as subjects.

Assessment of Study Quality: Study quality was judged by two researchers. The data were critically scrutinized for their quality and significance. Initial selection of research articles was performed by the first author and cross-checked by the second author. The reviewers extracted all data from four databases as shown in Figure1. Re-assessments were done at certain stages and disagreements on the inclusion of certain articles in the review between the first and second reviewer were reconciled by the third and fourth reviewers. The present review showed that the studies which contain most of the methodological necessities based on JADAD (Oxford Quality Scoring System) had $\geq 3$ points $(\geq+++)$, implying a high range of quality score; while those with some methodological issues had $\leq 2$ points $(\leq++)$, indicating a low range of quality score.

Critical Appraisal: Critical assessments regarding quality and internal validity were assessed via Strengthening the Reporting of Observational Studies in Epidemiology (STROBE, Von Elm et al., 2008) statements and Scottish Intercollegiate Guidelines Network (SIGN, 2001) checklist. The SIGN is a suitable checklist for judging the quality of case-control and cohort studies, while STROBE provides guidelines for observational and cross-sectional designs. Several questions such as: (i) Did the researchers state questions and objectives well? (ii) How well does the sample represent the population under study? (iii) Is the research procedure appropriate? (iv) Are the results properly discussed? (v) Do the results sufficiently answer research questions and realize study objectives? (vi) How comprehensive are the descriptions of the research design, country, sampling technique, sample size, measures and results of selected studies were used to appraise the studies as presented in Table 2 of the appendix section?

\section{Results}

The search identified 152,981 papers from four databases that investigated the relationship or effects of consumer ethnocentrism and collectivism on attitude towards locally manufactured products between 2009 and 2018. At the initial stage, duplicates were removed; this was followed by screening of the titles and abstracts of the remaining articles based on the inclusion criteria. Congruently, out of the 94 papers that scaled through at the initial screening process (based on title and abstract), only 83 of these were fully accessible and thus eligible for full-text review. Lastly, after a detailed evaluation of the full-text papers, only $11.75 \%$ was included for synthesis; others were discarded based on the exclusion criteria. Please see figure 1 for more clarifications. It is pertinent to note that the reviewers did not review unpublished works, and there was no manual search throughout the review process.

\section{Discussion}

The eight eligible studies included in the present review are comprehensively discussed under the two sub-sections (4.1 and 4.2) below.

\subsection{Consumer Ethnocentrism and Attitudes}

Consumers' attitudes towards locally manufactured high involvement products are dependent on consumers' attribution of importance to their home country economic well-being and beliefs towards national/community heritage. Findings from cross-sectional studies indicated that consumer ethnocentrism (CE) has a positive influence on attitude towards locally manufactured products (Yildiz, Heitz-Spahn, \& Belaud, 2018; Kumar, 
Fairhurst, \& Kim, 2013), and positively correlated with local brand preference (Shu, Stronbeck, \& Hsieh, 2013). In an exploratory study that re-conceptualized and cross-culturally validated consumer ethnocentrism scales, Sharma (2014) found that consumer ethnocentrism comprises of affective reaction, cognitive bias, and behavioral preference. In fact, Sharma (2014) posited that consumer ethnocentrism is an attitude construct. Both consumers with high ethnocentric tendencies and those with low ethnocentric tendencies exhibited similar attitudes towards locally manufactured products in Slovakia (Saffu et al., 2010). Slovakian consumers stressed that locally manufactured products possess better quality than imported ones (Saffu et al., 2010). The review argues that consumers tend to exhibit positive attitudes towards locally manufactured high involvement products on three grounds: (i) due to perceived utility of the product (ii) due to nationalism (iii) as a result of buy locally made campaign.

In another exploratory study, Pentz, Terblanche and Boshoff (2017) found that CE is positively associated with history of operation, individualism, and patriotism. These imply that, CE analyzes consumers' psychic state in relation to their temperament towards locally manufactured products. Thus, consumers' ethnocentric tendencies are inclined to increase when consumers realize a history of operation against their country/community, people exhibit preference for a loose social framework whereby they are expected to take care of only themselves and their immediate families, and people demonstrate or intend to demonstrate loyalty to their country. In both an exploratory study by Pentz et al. (2017) and a cross-sectional study by Kumar et al. (2011), cultural openness (CO) as an antecedent of consumer ethnocentrism was found to be negatively related to consumer ethnocentrism. This is an indication that when consumers resolve to establish bias against products manufactured in foreign countries, introducing or exposing them to other cultures worsens their ethnocentric tendencies. It is notable that different study designs from different geographical locations evidenced the negative relationship between $\mathrm{CO}$ and CE, implying that, replication of this investigation tends to yield similar results. Given this, it is concluded that consumer ethnocentrism influences attitude towards locally manufactured high involvement products. It also becomes pertinent to thoroughly review the link between consumer ethnocentrism and collectivism as to ascertain the direction of its relationship with CE. This is imperative as a result of both collectivism and CO being components of culture. Therefore, collectivism and CE, and their joint influence or chronological relationship with attitude is hereby presented in the second phase of the present review's discussion.

\subsection{Collectivism, Consumer Ethnocentrism, and Attitudes}

Empirical studies show that collectivism is related to consumer ethnocentrism (CE) and in turn CE is positively related to attitude towards locally manufactured high involvement products. Results based on a cross-sectional study conducted by He and Wang (2015) reveal that cultural identity is moderately correlated with CE. In fact, the authors inferred that out of the four dimensions of cultural identity (cultural homogeneity, belief structure, national heritage, and ethnocentrism) in their study, that exploratory factor analysis loaded national heritage and cultural homogeneity dimensions into one factor which reflects identification with one's culture, while belief structure was not reflected in their study samples; thus, belief structure did not load on any factor and was discarded. Consequently, He and Wang (2015) found that cultural identity is positively related to locally manufactured brand preference, whereas $\mathrm{CE}$ had no significant impact on locally manufactured brand preference. This shows that the sample lack belief structure which is believed to strengthen their cultural heritage facet and in turn emboldens consumer ethnocentrism. No doubt, consumers' attitudes towards locally manufactured high involvement products will likely be unfavorable without consumers' collective goals which include beliefs in existing structures or traditions.

In a cross-sectional study conducted by Kumar et al. (2013, 2011), collectivism showed a positive relationship with CE, and thereafter, CE depicted a positive relationship with attitude towards locally manufactured products. This indicates that consumers' attitudes towards locally manufactured high involvement products hinge on consumers' ethnocentric tendencies which is determined by consumers' collectivistic temperaments (Kumar et al., 2013); nationalistic tendencies, patriotic tendencies, history of operation, individualistic tendencies, and cultural openness (Pentz et al., 2017); cultural identity which encompasses beliefs in cultural heritage/cultural identity (He \& Wang, 2015). It is surprising that two studies offered contrary views on the antecedents of CE: while Pentz et al. (2017) found individualism as an antecedent of CE, Kumar et al. (2013; 2011) evidenced that collectivism is an antecedent of CE. Expectedly, collectivism will trigger consumer ethnocentrism in a society embedded in belief structure, whereby, societal well-being and interests surpasses individual goals. On the contrary, individualism is believed to be a factor of consumer ethnocentrism in high technological industrialized societies; whereby, their ethnocentric tendencies hinge on the perceived utility they will derive from establishing bias against products from other countries. Thus, the tendency of individualism transforming into $\mathrm{CE}$ is viewed through low technological sophistication of foreign products' country of origin. 
Correspondingly, the above sections have buttressed our notion of viewing collectivism and CE from Triandis lens. This is based on both constructs' positive relationship with each other; and thereafter, positively influenced attitudes towards locally manufactured high involvement products (Kumar et al., 2013, 2011). In view of this, the authors assert that collectivism is proximal antecedent of CE necessary for exhibition of positive attitudes towards locally manufactured products. Relying on the above assertion, we argue that collectivism goes beyond group interests to ensure maintenance of cultural heritage, social stability, and population density to influence CE. This, cum Sharma (2014) findings that revealed ethnocentrism as attitude construct consisting of affective reaction, cognitive bias, and behavioral preference answers the first review question (Is the acclaimed influence of consumer ethnocentrism and collectivism on consumers' attitudes towards locally manufactured high involvement products truly a psychological process?). Premised on extant literatures, the influences of collectivism and CE are truly psychological process. This is owing to the fact that consumers ponder over issues that affect them such as: lack of access to desired products, high unemployment rate and country's declining economy, and in turn respond through various decision making processes including exhibiting positive attitudes towards locally manufactured high involvement products. These critical issues associated with consumers' lives may rouse low ethnocentric consumers develop positive attitude towards locally made high involvement products.

Interestingly, consumers from less industrialized and middle income economy such as Slovakia have positive attitudes towards locally manufactured high involvement products (Saffu et al., 2010) irrespective of their ethnocentric dispositions. While it is believed to be as a result of Slovakia government's buy local campaign, we state that consumers resort to locally manufactured high involvement products due to their nationalistic spirit. Relying on Saffu et al. (2010), responses from both student group consumers and non-student group consumers on CETSCALE pertained to nationalism; implying that, in the absence of perceived utility from a locally manufactured high involvement product, consumers' social issues will likely reinforce nationalistic spirit in low ethnocentric consumers which leads to positive attitude towards locally manufactured high involvement products. Thus, the second review question (In what way do consumer ethnocentrism and collectivism catalyze consumers' attitudes) derives respite from the practical role of nationalism; history of operation, patriotism as antecedents of CE (Pentz et al., 2017); collectivism and CE as joint antecedents of positive attitudes towards locally manufactured high involvement products (Kumar et al., 2013, 2011); consumer ethnocentrism as a determinant of locally manufactured high involvement product (Shu et al., 2013).

Continuing, consumers' attitudes towards locally manufactured high involvement products tend to develop positively when consumers analyze social issues that are central to their existence both as consumers and as a nation. For instance, Kumar et al. (2011) found that perceived personal threat (of consumers) and perceived domestic threat (of a country's economy) moderates the relationship between $\mathrm{CE}$ and attitude towards domestic brand preference; implying that consumers' disposition to adjustments on attitudes towards locally manufactured high involvement products is affected by the level of perceived economic threat. CE and collectivism catalyze consumers' attitudes towards locally manufactured high involvement products in two ways: (i) emotionally (ii) rationally. It is believed that $\mathrm{CE}$ and collectivism spurring of consumers attitudes towards locally manufactured high involvement products is based on rationality in individualized societies. Thus, we argue that low ethnocentric consumers tend to be individualistic in nature and could only exhibit positive attitudes towards locally manufactured high involvement products when they perceived functionality of the product. Consumers in this category are normative ethnocentric consumers because they override internal sentiments and play by marketing rules.

Contrarily, CE and collectivism stimulates consumers' attitudes towards locally manufactured high involvement products on emotional grounds; hence, Sharma (2014) pointed out that consumer ethnocentrism is an attitude construct, and has affective dimension. Undoubtedly, affective reaction triggers emotion in consumers because they attribute values to resources spent on locally manufactured high involvement products due to its effect on their country's economic status, and in various cases acquire or consume locally manufactured high involvement products based on their patriotic and/or nationalistic tendencies. We posit that emotionally driven attitudes towards locally manufactured high involvement products breed dogmatism and conservatism among consumers. As a consequence, extant literatures deduced that conservative consumers are more ethnocentric in nature, and are inclined to demonstrate positive attitudes towards locally manufactured high involvement products. Consumers in this category are affective ethnocentric consumers, whereby, they evaluate the effects of developing a positive or negative attitude towards locally manufactured high involvement products to their immediate society. However, He and Wang (2015) finding casts doubt into our thoughts since CE associated negatively with preference for import brands but was insignificantly associated with preference for domestic 
brands. Thus, such CE may not trigger positive behavioral preference towards locally manufactured high involvement products.

\section{Conclusion}

The current review has presented facts about consumers' attitudes towards locally manufactured high involvement products. It was revealed that collectivism and consumer ethnocentrism are positively related, and in turn, consumer ethnocentrism influences consumers' attitudes towards locally manufactured high involvement products. Contrary to our initial expectation, individualism was found to be related to consumer ethnocentrism which casts doubt on the existence of negligible size of Idiocentrics in collectivist cultures. One of the major findings is that consumer ethnocentrism consists of affective reaction, cognitive bias, and behavioral preference (Sharma, 2014), which is the pillar of the review's stance on CE and collectivism spurring consumers' attitudes towards locally manufactured high involvement products emotionally.

In addition, review of ten years range of studies showed no significant change among contemporary consumers from Triandis lens; as a result, collectivism and consumer ethnocentrism are indubitable antecedents of attitude towards locally manufactured high involvement products. Hence, the review offered a limelight answer to questions posed in the early section by establishing that the influences of $\mathrm{CE}$ and collectivism on attitudes towards locally manufactured high involvement products are truly a psychological process. Consequently, the review revealed that $\mathrm{CE}$ and collectivism catalyze consumers' attitudes towards locally manufactured high involvement products through consumers' emotions and rationales. While it was highlighted earlier that consumers exhibit positive attitudes towards locally manufactured high involvement products due to perceived utility of the product, nationalism, and as a result of buy locally made campaign, the implication is that in high ethnocentric societies, transitioning economies manufacturing high involvement products will become stronger, and absolve their country the dangers of being a dumping ground for consumer products. In low ethnocentric societies, local firms manufacturing high involvement products should engage in promotional offers such as: free delivery/shipment, long-time free maintenance after product purchase, and stress-free trade-in of fairly used products.

Bearing in mind that the present review process is not without flaws, it is noted that lack of access to some papers limited the number of eligible studies identified during the review process which should have added to the retrieved facts on the subject matter. The reviewers did not use synonyms for the constructs, which may have affected the range of literature that was evaluated. There was restriction to peer reviewed articles in the present review; unpublished articles, conference papers, theoretical and conceptual papers were excluded, which may have affected the size of reviewed studies and thus tend to limit generalizability of the findings across literatures. Moreover, both Pentz and Sharma's studies are exploratory; these studies created room for further research to fill the methodological gaps. Hence, varied research designs tend to affect the study outcome. It is also suggested that further reviews be conducted to incorporate unpublished articles, conference papers, theoretical and conceptual papers to bolster extant findings. While the government should intensify campaign for buy local products and reduce taxes for consumption of locally made high involvement products as a motivation to local consumers, we infer that lack of exposure to mass media tend to affect buy locally made products' campaign. Therefore, it is advised that consumers be empowered to unlimited access to mass media for robust benefit of the campaign. In the face of a contrary finding such as individualism being positively related to consumer ethnocentrism, further studies should be conducted to confirm the existing finding.

\section{References}

Acharya, C., \& Elliott, G. (2003). Consumer ethnocentrism, perceived product quality and choice: An empirical investigation. Journal of International Consumer Marketing, 15(4), 87-115.

Ajzen, I. (1991). The theory of planned behavior. Organizational Behavior and Human Decision Processes, 50(2), 179-211. https://doi.org/10.1016/0749-5978(91)90020-t

Bagozzi, R. P., Gopinath, M., \& Nyer, P. U. (1999). The role of emotions in marketing. Journal of the Academy of Marketing Science, 27(2), 184-206. https://doi.org/10.1177/0092070399272005

Bizumic, B., Duckitt, J., Popadic, D., Dru, V., \& Krauss, S. (2008). A cross-cultural investigation into a reconceptualization of ethnocentrism. European Journal of Social Psychology, 39(6), 871-899. https://doi.org/10.1002/ejsp.589

Cameron, R. C., \& Elliott, G. R. (1998). The 'Country-of-Origin Effect' and Consumer Attitudes to 'Buy Local' Campaigns: Australian Evidence. Australasian Marketing Journal (AMJ), 6(2), 39-50. https://doi.org/10.1016/S1441-3582(98)70248-4 
Chang, W. J., Liao, S. H., \& Wu, T.-T. (2017). Relationships among Organizational Culture, Knowledge Sharing, and Innovation Capability: A Case of the Automobile Industry in Taiwan. Knowledge Management Research \& Practice, 15, 471-490. https://doi.org/10.1057/s41275-016-0042-6

Correa, S., \& Parente-Laverde, A.-M. (2017). Consumer Ethnocentrism, Country Image and Local Brand Preference: The Case of the Colombian Textile, Apparel and Leather Industry. Global Business Review, 18(5), 1111-1123. https://doi.org/10.1177/0972150917710112

Eagly, A. H., \& Chaiken, S. (2007). The advantages of an inclusive definition of attitude. Social Cogn, 25(5), 582-602. https://doi.org/10.1521/soco.2007.25.5.582

Earley, P. C., \& Gibson, C. B. (1998). Taking stock in our progress on individualism-collectivism: 100 years of solidarity and community. Journal of Management, 24(3), 265-304.

Elliott, G. R., \& Cameron, R. C. (1994). Consumer Perception of Product Quality and the Country-of-Origin Effect. Journal of International Marketing, 2(2), 49-62. Retrieved February 13, 2020, from www.jstor.org/stable/25048542

Fishbein, M., \& Ajzen, I. (1975). Belief, Attitude, Intention, and Behavior: An Introduction to Theory and Research. Addison-Wesley Publishing Co., Reading, MA: Addison-Wesley Pub Co.

He, J., \& Wang, C. L. (2015). Cultural identity and consumer ethnocentrism impacts on preference and purchase of domestic versus import brands: An empirical study in China. Journal of Business Research, 68(6), 1225-1233. https://doi.org/10.1016/j.jbusres.2014.11.017

Hofstede, G., Hofstede, G. J., \& Minkov, M. (2010). Cultures and Organizations: Software of the Mind (Rev. 3rd ed.). New York: McGraw-Hill. Translations available at: www.geerthofstede.nl and "our books".

Huang, C. C., \& Lu, L. C. (2015). Examining the Roles of Collectivism, Attitude Toward Business, and Religious Beliefs on Consumer Ethics in China. Journal of Business Ethics, 146(3), 505-514. https://doi.org/10.1007/s10551-015-2910-z

Jadad, A. R., Moore, R. A., \& Carroll, D. (1996). Assessing the quality of reports of randomized clinical trials: is blinding necessary?. Control Clin Trials, 17(1), 1-12. PMID: 8721797.

Koubaa, Y., Ulvoas, G., \& Chew, P. (2011). The dual impact of traditional and national cultural values on expatriate ethnic groups' attitudes and willingness to buy. Asia Pacific Journal of Marketing and Logistics, 23(5), 626-640. https://doi.org/10.1108/13555851111183066

Kumar, A., Fairhurst, A., \& Kim, Y.-K. (2011). Ethnocentric tendencies of Indian consumers: impact on preference for domestic versus foreign products. The International Review of Retail, Distribution and Consumer Research, 21(4), 323-341. https://doi.org/10.1080/09593969.2011.595496

Kumar, A., Fairhurst, A., \& Kim, Y.-K. (2013). The role of personal cultural orientation in consumer ethnocentrism among Indian consumers. Journal of Indian Business Research, 5(4), 235-250. https://doi.org/10.1108/jibr-02-2013-0018

Lazarus, R. S. (1991). Emotion and Adaptation. Oxford University Press, New York, NY.

Pentz, C., Terblanche, N., \& Boshoff, C. (2017). Antecedents and consequences of consumer ethnocentrism: evidence from South Africa. International Journal of Emerging Markets, 12(2), 199-218. https://doi.org/10.1108/ijoem-09-2015-0189

Perner, L. (2010). Consumer behavior: The psychology of marketing. Retrieved from http://www.consumerpsychologist.com/

Ramadania, Gunawan, S., \& Rustam, M. (2015). Cultural Similarity, Consumer Ethnocentrism and Product Necessity in Evaluation of Malaysian Products: Indonesian Consumer Perspective. Procedia-Social and Behavioral Sciences, 211, 533-540. https://doi.org/10.1016/j.sbspro.2015.11.071

Rosenberg, M. J., \& Hovland, C. I. (1960). Cognitive, Affective and Behavioral Components of Attitudes. In M. J. Rosenberg, \& C. I. Hovland (Eds.), Attitude Organization and Change: An Analysis of Consistency among Attitude Components. Yale University Press, New Haven.

Saffu, K., Walker, J. H., \& Mazurek, M. (2010). The role of consumer ethnocentrism in a buy national campaign in a transitioning country. International Journal of Emerging Markets, 5(2), 203-226. https://doi.org/10.1108/17468801011031829

Sharma, P. (2014). Consumer ethnocentrism: Reconceptualization and cross-cultural validation. Journal of 
International Business Studies, 46(3), 381-389. https://doi.org/10.1057/jibs.2014.42

Shu, S. T., Strombeck, S., \& Hsieh, C. L. (2013). Consumer ethnocentrism, self-image congruence and local brand preference: A cross-national examination. Asia Pacific Management Review, 18(1), 43-61. https://doi.org/10.6126/APMR.2013.18.1.03

Sreen, N., Purbey, S., \& Sadarangani, P. (2018). Impact of culture, behavior and gender on green purchase intention. Journal of Retailing and Consumer Services, 41, 177-189. https://doi.org/10.1016/j.jretconser.2017.12.002

The Ministry of Finance Malaysia. (2019). The Malaysian Insight-Buy local campaign helps local firms expand their markets. Retrieved February 21, 2020 from https://www.treasury.gov.my/index.php/en/galleryactivities/news/item/4868-the-malaysianinsight-buy-local-campaign-helps-local-firms-expand-their-markets -lim.html

Triandis, H. C. (2000). Culture and Conflict. International Journal of Psychology, 35(2), $145-152$. https://doi.org/10.1080/002075900399448

Triandis, H. C. (2001). Individualism-collectivism and personality. Journal of Personality, 69, 907-924.

Vincent-Osaghae, G., \& Ugiagbe, E. O. (2018). Millenial Consumer Syndrome in a Developing Nation: Exploring the Attitude of Nigerians to Locally Made Goods. Mediterranean Journal of Social Sciences, 9(3), 151-164. https://doi.org/10.2478/mjss-2018-0057

Von Elm, E., Altman, D. G., Egger, M., Pocock, S. J., Gotzsche, P. C., \& Vandenbroucke, J. P. (2008). The Strengthening the Reporting of Observational Studies in Epidemiology (STROBE) statement: guidelines for reporting observational studies. Journal of Clinical Epidemiology, 61(4), 344-349. https://doi.org/10.1016/j.jclinepi.2007.11.008

Yildiz, H., Heitz-Spahn, S., \& Belaud, L. (2018). Do ethnocentric consumers really buy local products? Journal of Retailing and Consumer Services, 43, 139-148. https://doi.org/10.1016/j.jretconser.2018.03.004 


\section{Appendix}

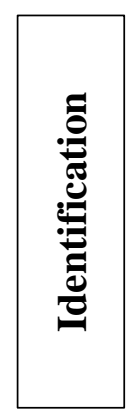

Records identified through databases searching: $(n=152,981)$

- Science Direct: 35,166

- Emerald Insight: 16,907

- Springer Link: 41,669

- Scopus: 59,239
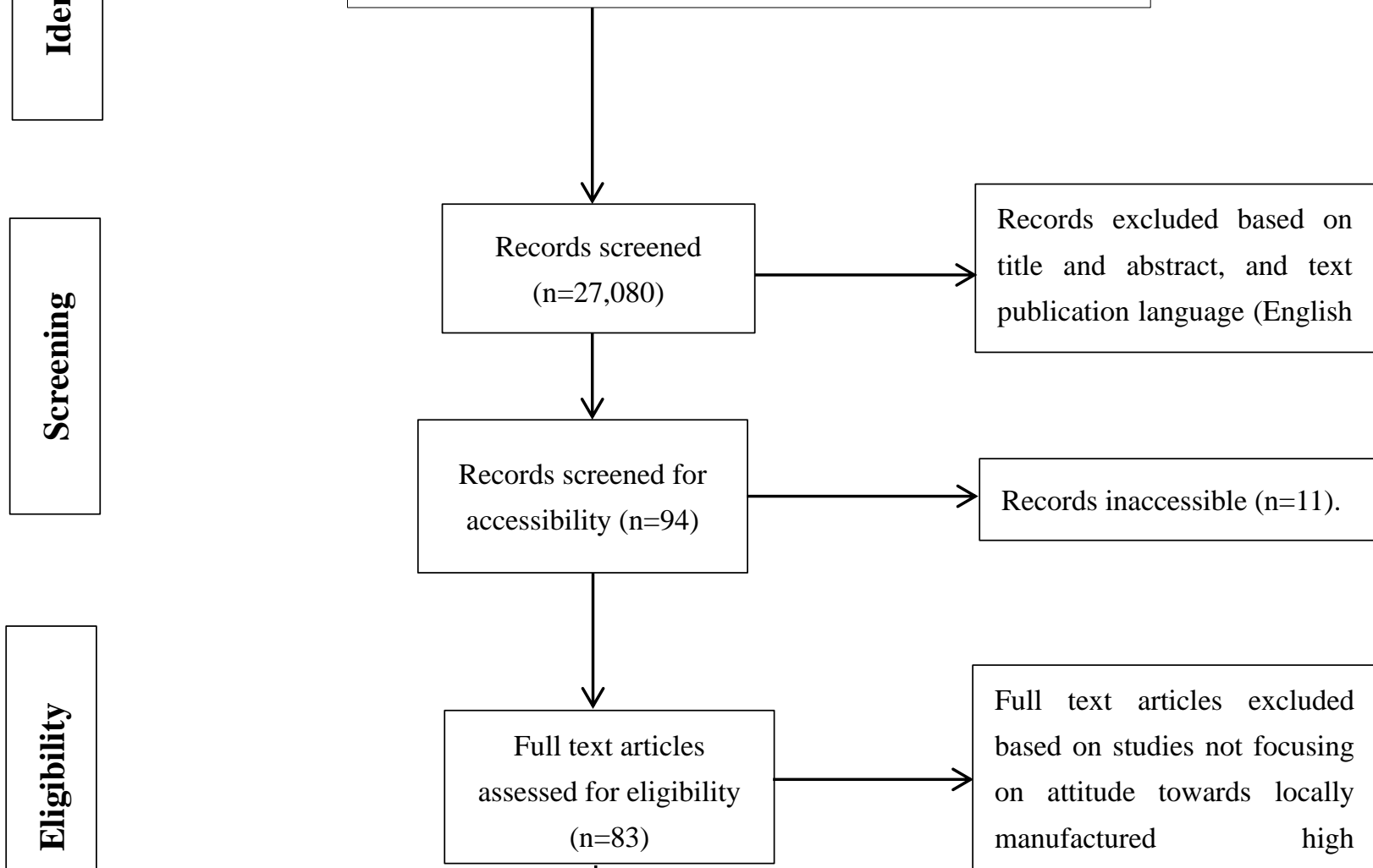

Figure 1. Systematic review flow diagram 
Table 1. Description of studies centered on attitude towards locally manufactured high involvement products that have been included in the synthesis

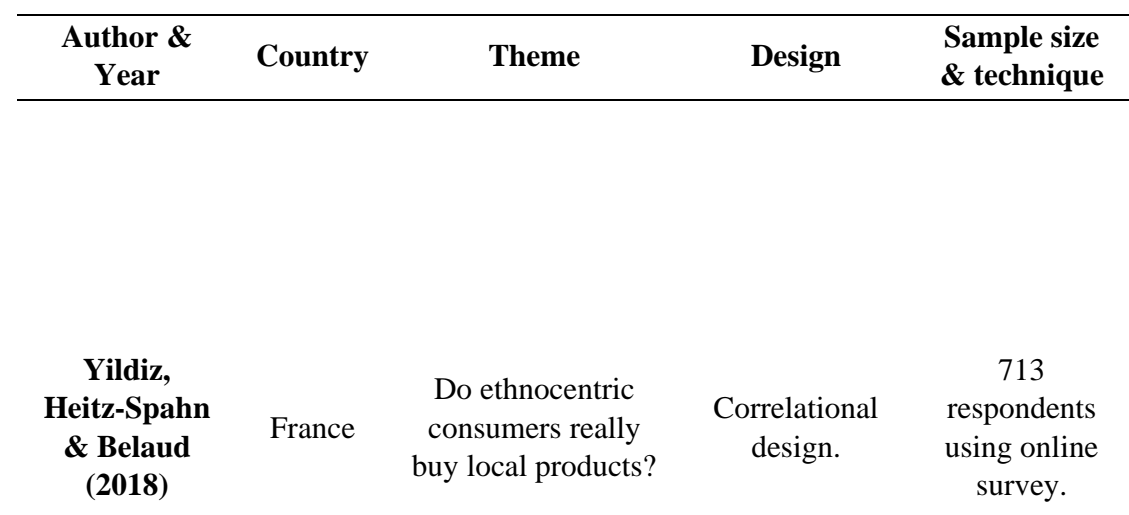

Findings

Consumer ethnocentrism (CE) $(\boldsymbol{\beta}=$ $0.498 * * *)$ positively influences attitude towards local products, purchase of local products $\left(\beta=0.106^{* * *}\right)$, purchase of global products $\quad(\beta=0.108 * * *), \quad$ but negatively influences attitude towards global products $(\beta=$ $-0.332 * * *)$. Local behavioral commitment positively influences attitude towards local products $(\beta=0.322 * * *)$, and purchase of local products $\quad(\beta=0.247 * * *), \quad$ but negatively influences attitude towards global products $(\beta=$ $-0.012 * * *)$, and purchase of global products $(\beta=-0.233 * * *)$.

History of operation $(\boldsymbol{\beta}=\mathbf{0 . 3 3} * * *)$, individualism $(\boldsymbol{\beta}=\mathbf{0 . 2 6} * * *)$ and patriotism $(\boldsymbol{\beta}=\mathbf{0 . 2 8 *})$ have positive influences on consumer ethnocentrism (CE), whereas cultural openness $(\boldsymbol{\beta}=-\mathbf{0 . 2 6} * *)$ has negative influence on $\mathrm{CE}$; $\mathrm{CE}$ $(\boldsymbol{\beta}=\mathbf{- 0 . 6 4 * * * )}$ negatively influences on attitude towards importing, while

\begin{tabular}{|c|c|c|c|c|}
\hline $\begin{array}{c}\text { Pentz, } \\
\text { Terblanche }\end{array}$ & South & $\begin{array}{c}\text { Antecedents and } \\
\text { consequences of } \\
\text { consumer }\end{array}$ & Exploratory & $\begin{array}{c}759 \text { (417 } \\
\text { black and } 342 \\
\text { white) }\end{array}$ \\
\hline$\& \underset{(2017)}{\text { Boshoff }}$ & Africa & $\begin{array}{l}\text { ethnocentrism: } \\
\text { evidence from } \\
\text { South Africa. }\end{array}$ & design. & $\begin{array}{l}\text { respondents } \\
\text { with online } \\
\text { survey. }\end{array}$ \\
\hline
\end{tabular}
attitude towards importing $(\beta=0.71 * * *)$ positively influences imports purchase intention among black samples. Patriotism $(\boldsymbol{\beta}=\mathbf{0 . 2 4} * *), \quad$ individualism $(\boldsymbol{\beta}=\mathbf{0 . 1 7} *)$, nationalism $(\boldsymbol{\beta}=\mathbf{0 . 1 7} *)$, and history of operation $(\boldsymbol{\beta}=\mathbf{0 . 3 7} * * *)$ positively influence $\mathrm{CE}$, whereas cultural openness $(\boldsymbol{\beta}=\mathbf{- 0 . 2 3} * *)$ negatively influence $\mathrm{CE}$; $\mathrm{CE}(\beta=-0.61 * * *)$ negatively influences attitude towards importing, while attitude towards importing $(\beta=0.78 * * *)$ positively influences imports purchase intention among white samples.

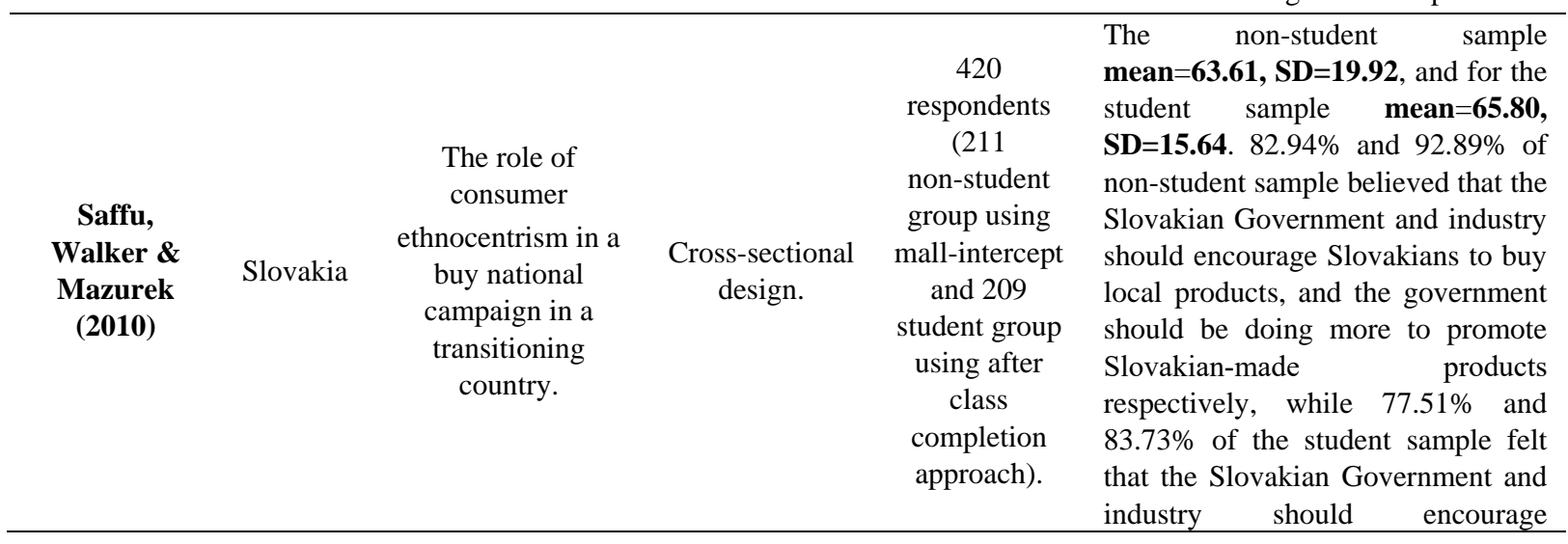


Slovakians to buy local products, and the government should be doing more to promote Slovakian-made products respectively. Both samples indicated positive correlations on innovativeness and design of Slovakian made products rho $=\mathbf{0 . 2 8 9} *$ (non-students),

rho $=\mathbf{0 . 1 3 8} * \quad$ (students); buying Slovakian product wherever possible rho $=\mathbf{0 . 5 5 8} *$ (non-students), rho $=\mathbf{0 . 3 2 0} *$ (students); looking for Slovakian made products when shopping rho $=\mathbf{0 . 5 0 4} *$ (non-students) rho $=231 *$ (students).

Study 1 assessed the new items' properties psychometrically which helped to ascertain its validity in four countries of the study location; exploratory factor analysis (EFA) loaded 18 items which explained $73 \%(42 \%, 18 \%$, and $13 \%)$ variance in consumer ethnocentrism 2504 retail with 6 items loading each on 3

\begin{tabular}{|c|c|c|c|c|}
\hline $\begin{array}{c}\text { Sharma } \\
\text { (2014) }\end{array}$ & $\begin{array}{l}\text { China, } \\
\text { India, } \\
\text { UK, and } \\
\text { USA. }\end{array}$ & $\begin{array}{c}\text { Consumer } \\
\text { ethnocentrism: } \\
\text { Reconceptualization } \\
\text { and cross-cultural } \\
\text { validation. }\end{array}$ & $\begin{array}{c}\text { Exploratory } \\
\text { design. }\end{array}$ & $\begin{array}{c}\text { shoppers via } \\
\text { mall intercept } \\
\text { survey (study } \\
\begin{array}{c}1=1056 \text {, and } \\
\text { study } \\
2=1448) .\end{array}\end{array}$ \\
\hline
\end{tabular}
factors namely: affective reaction, cognitive bias, and behavioral preference. Study 2 found that affective reaction, cognitive bias, and behavioral preference are moderately correlated $(\mathbf{r}=\mathbf{0 . 2 7}$ to 0.36, $p<0.001)$. Consumer ethnocentrism and CETSCALE ( $\mathrm{r}=$ $=0.42 * * *)$, consumer animosity $(\mathrm{r}=$ $\left.0.14^{* *}\right)$, national identification ( $\mathrm{r}$ $=0.18 * *)$, patriotism $(\mathrm{r}=0.27 * * *)$, nationalism $(\mathrm{r}=0.23 * * *)$, internationalism $(\mathrm{r}=-0.22 * * *)$ and cosmopolitanism $(\mathrm{r}=-0.25 * * *)$.

Consumer ethnocentrism (CE) ( $\beta$ Taiwan $=.214$, $\mathbf{p}<\mathbf{0 . 1}$;

$\boldsymbol{\beta}$ Korea=.229, $\quad \mathbf{p}<.05)$, self-image congruence (SIC) ( $\beta J a p a n=.372$, $\mathrm{p}<.01)$, and product knowledge (PK) $\quad(\beta J a p a n=.253, \quad \mathrm{p}<0.1$; $\beta$ Korea $=.230, \quad \mathrm{p}<.01) \quad$ influenced local brand preference (LBP) for beer. CE ( $\beta$ Taiwan $=.560, p<0.01$;

Consumer

Taiwan, Ethnocentrism,

Shu, Japan, Self-Image Stronbeck \& and

Hsieh (2013) South

Korea.
Congruence and Local Brand Preference: A cross-national examination.
716

Cross-sectional design.

consumers using mall-intercept. $\beta$ Korea $=.306, p<.01, \beta J a p a n=.216$, $\mathbf{p}<.005)$, PK $(\beta$ Korea $=.181, \mathrm{p}<.005$ impacted local brand preference for cosmetics; CE ( $\beta$ Korea $=.261, p<.05$; $\beta J a p a n=.218, \mathrm{p}<.01)$ also impacted SIC for cosmetics. CE in model 1-1 ( $\beta J a p a n=.201, \quad \mathrm{p}<0.1)$ impact on LBP reduced than in model 1 $(\beta J a p a n=.239, p<.005)$ after adding SIC as mediator ( $\beta$ Japan $=.172$, $\mathrm{p}<.01)$ for cosmetics. $\mathbf{C E}$ ( $\beta$ Taiwan=.303, $\quad \mathbf{p}<.01), \quad \mathrm{PK}$ $(\beta$ Korea $=.288, \mathrm{p}<.005)$ influenced LBP for PC notebook, CE 
(ßJapan=.361, $\quad \mathrm{p}<.01) \quad$ also influenced SIC.

Cultural openness $(\boldsymbol{\beta}=\mathbf{- 0 . 1 5 4})$, and collectivism $(\boldsymbol{\beta}=\mathbf{0 . 1 9 1 *})$ influenced consumer ethnocentrism (CE); $\mathrm{CE}$ $(\boldsymbol{\beta}=\mathbf{0 . 2 2 8} *$ mobile service) and ( $\beta=0.272 *$ soap $)$ influenced attitude towards domestic products, while

Ethnocentric

Kumar,

Fairhurst \& India.

Kim (2011) tendencies of Indian

consumers: impact

on preference for

domestic versus

foreign products.
Cross-sectional design.
800

respondents using geographical cluster sampling. CE $(\beta=-0.227 *$ mobile service) and ( $\beta=-0.263$ *soap) influenced attitude towards foreign products. Perceived personal threat $\left(\Delta \chi^{2} / \Delta \mathrm{df}-31.23 / 1 * *\right)$ and perceived domestic threat $\left(\Delta \chi^{2} / \Delta \mathrm{df}-12.13 / 1^{* *}\right)$ moderated the relationship between $\mathrm{CE}$ and attitude towards domestic mobile service. Similarly, perceived personal threat $\left(\Delta \chi^{2} / \Delta \mathrm{df}-27.5 / 1 * *\right)$ and perceived domestic threat $\left(\Delta \chi^{2} / \Delta\right.$ df-14.47/1**) moderated the relationship between $\mathrm{CE}$ and attitude towards domestic soap.

Cultural identity (CI) $(\beta=.093 * * *)$ is associated with domestic brand preference and $(\beta=.071 *)$ with domestic brand purchase, while CI ( $\left.\beta=-.078^{* *}\right)$ is negatively associated with import brand purchase. CE

Cultural identity and consumer ethnocentrism impacts on

He \& Wang
$(\mathbf{2 0 1 5})$ preference and purchase of domestic versus import brands: An empirical study in China.
912

consumers from mixed background using random sampling technique. $(\boldsymbol{\beta}=\mathbf{. 0 7 2} *)$ is negatively associated with preference for import brands. Brand equity $(\mathrm{BE})(\beta=.668 * * *)$ on domestic brands and $(\beta=.612 * * *)$ on import brands preferences respectively, while $\mathrm{BE}(\beta=.518 * * *)$ on domestic brand and $(\beta=.440 * * *)$ on import brand purchases respectively. $\mathrm{BE} \times \mathrm{CI}(\beta=.063 *)$ on domestic brand preference, $\left(\beta=.065^{*}\right)$ on import brand preference, and $\left(\beta=.105^{* *}\right)$ for purchase of import brands. $\mathrm{CE} \times \mathrm{BE}$ $\left(\beta=-.115^{* * *}\right)$ on domestic brand preference.

Collectivism $\quad(\boldsymbol{\beta}=\mathbf{0 . 2 8 1 *}), \quad$ power distance $\quad(\boldsymbol{\beta}=\mathbf{0 . 3 7 0} *), \quad$ and

The role of personal cultural orientation

Kumar,

Fairhurst \& India.

Kim (2013) in consumer

ethnocentrism

among Indian

consumers.
$800 \quad$ uncertainty avoidance $(\boldsymbol{\beta}=\mathbf{0 . 1 7 3} *)$, respondents consumer ethnocentrism (CE); CE using geographical cluster sampling approach. consumer ethnocentrism (CE); CE
$(\boldsymbol{\beta}=\mathbf{0 . 3 8 4} *$ mobile service) and ( $\beta=0.361^{*}$ soap) influenced attitude towards domestic products, while CE $(\boldsymbol{\beta}=-\mathbf{0 . 3 1 5} *$ mobile service) and $(\beta=-0.299 *$ soap $)$ influenced attitude towards foreign products.

NB: Findings in bold indicate constructs and their influences/relationship of interest in the present review. 
Table 2. Critical Assessment of study quality

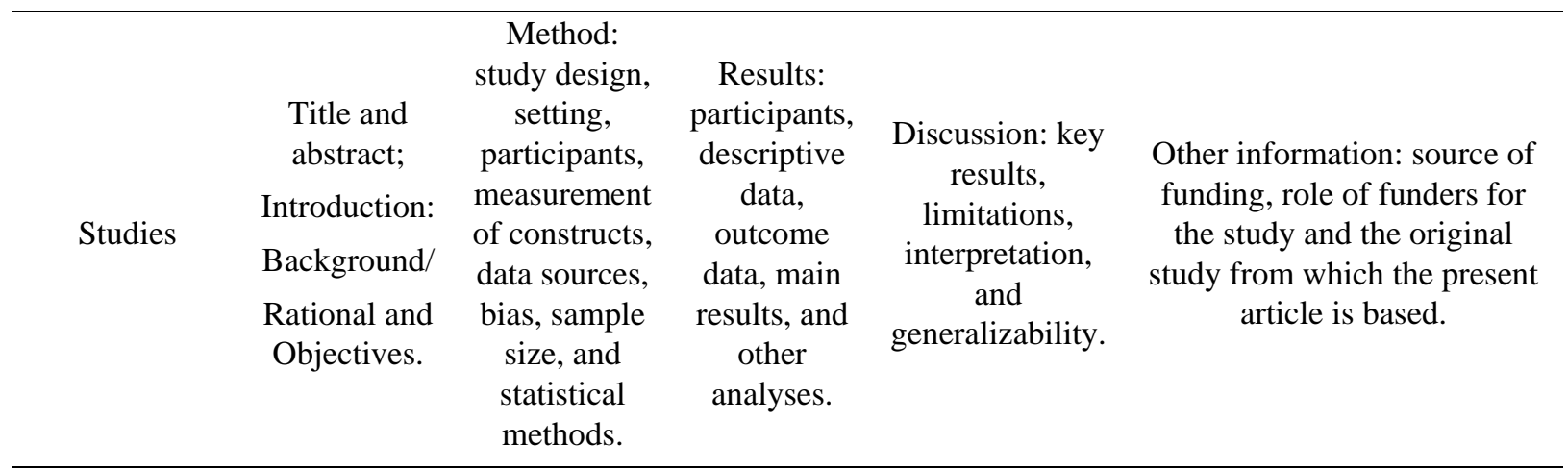

\section{Ethnocentrism}

\section{Pentz,}

Terblanche \&

Boshoff

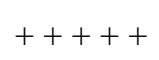

$+++$

$++++$

$++++$

(2017)

Yildiz,

Heitz-Spahn

\& Belaud

$$
+++
$$

$+++$

$++++$

$++++$

(2018)

Saffu, Walker

\& Mazurek

(2010)

Sharma

(2014)

$$
++++
$$

$+++$

$+++$

$++++$

Shu,

Stronbeck \&

$$
++
$$

$+++$

$++$

$++$

Hsieh (2013)

Kumar,
Fairhurst \&

Kim (2011)

Kumar,

Fairhurst \&

Kim (2013)

Collectivism

He \& Wang

$$
\text { (2015) }
$$

$$
+++
$$

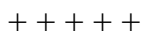

$++++$

$+++$

Note: Studies that are ranked $\geq 3$ points $(\geq+++)$ denote high quality studies, while studies with $\leq 2$ points $(\leq++)$ rank denote low quality based on Oxford Quality Scoring System.

\section{Copyrights}

Copyright for this article is retained by the author(s), with first publication rights granted to the journal.

This is an open-access article distributed under the terms and conditions of the Creative Commons Attribution license (http://creativecommons.org/licenses/by/4.0/). 